\title{
Glucose Control in the (Neuro) Intensive Care Unit
}

\section{Michael Moussouttas, MD}

Department of Neurology, Thomas Jefferson University, Philadelphia, PA

\section{Introduction}

The vexing question of optimal glucose level in the intensive care unit has long perplexed intensivists. Hyperglycemia is a natural response to physiologic stress, ${ }^{1}$ and in the critically ill patient has been attributed to inflammatory processes, insulin counter-regulatory hormones, organ dysfunction, iatrogenic carbohydrate or medication related hyperglycemia, and insulin resistance as evidenced by concurrently elevated insulin levels. ${ }^{1}$ Hyperglycemia occurs in $50-75 \%$ of patients admitted to an ICU, and has been associated with various adverse outcomes including increased mortality, organ dysfunction, susceptibility to infections, and neurological complications. ${ }^{1,2}$ On the cellular level, tissue/organ damage is theorized to be mediated via the production of toxic polyol metabolites and reactive oxygen species, ${ }^{3}$ with compromise of mitochondrial/cellular function. ${ }^{1}$ At the opposite extreme, hypoglycemia is acutely detrimental and clearly mandates avoidance. Glucose variability has also been linked to adverse outcomes, ${ }^{4}$ and insulin administration itself has been associated with increased mortality. ${ }^{5}$ As such, it is believed that resolution of hypoglycemia, and not insulin administration, is the determinant of improved outcomes. ${ }^{5}$

The dilemma facing intensive care physicians therefore lies in achieving a balance between the two detrimental extremes of hyperglycemia and hypoglycemia. Despite the completion of large randomized multicenter trials, the ideal glucose range to which treatment is targeted remains uncertain, and in fact there remains speculation as to whether glucose levels require treatment at all. Nevertheless, a familiarity with the available literature is imperative for the intensivist aspiring to achieve desirable outcomes for patients. The preponderance of literature pertaining to glycemic management in the ICU comes from non-neurological patients, and data regarding optimal glucose control in the NICU is therefore scant. As such, this article will review the available literature pertaining to hyperglycemic management in the ICU, with particular attention to patients with neurological conditions.

\section{Complications of Hyperglycemia}

Multiple studies have demonstrated an association between hyperglycemia and adverse outcomes, including mortality, and morbidity in terms of systemic multi-organ dysfunction and various adverse neurological outcomes. Systemic morbidity from hyperglycemia has included such adverse events as respiratory failure in the form of prolonged ventilator dependence, renal insufficiency, anemia and greater need for transfusions, and increased risk for infections and sepsis. ${ }^{6.7}$ Neurological consequences have involved elevations in intracranial pressure, cerebral herniation, greater frequency of epileptic episodes, ICU related polyneuromyopathy, and unfavorable outcomes based on measures of functional status. ${ }^{8,9}$ Hyperglycemia has been identified as a predictor of unfavorable outcomes in trauma patients, ${ }^{10}$ and in those with cardiovascular and cerebrovascular disease, ${ }^{11,12}$ and in SAH hyperglycemia has been related to the occurrence of vasospasm and poor outcome. ${ }^{8}$ Observational studies comparing intensive insulin therapy (IIT) to conventional therapy have suggested a possible benefit to IIT in terms of mortality and organ failure, ${ }^{5,13}$ obviating the need for more conclusive clinical trials.

\section{Randomized Clinical Trials}

Several large randomized trials have attempted to identify an optimal glucose range within which favorable outcomes are maximized and adverse events minimized. In a prospective, randomized, controlled (but unblinded) landmark study of 1548 SICU patients, IIT (target glucoselevels 80-100mg/ dl) was compared to conventional therapy (glucose $180-200 \mathrm{mg} / \mathrm{dl}$ ). ${ }^{7}$ Intensive therapy resulted in a lower morality rate $(4.6 \%$ vs. $8 \%$ ), mostly in those with ICU stays $>5$ days, and mostly in those dying from sepsis and multi-organ failure. ${ }^{7}$ IIT also reduced overall in-hospital mortality, duration of ventilator dependence, acute renal failure, hyperbilirubinemia, anemia, bacteremia, and critical illness polyneuropathy. ${ }^{7}$

In a follow-up study with similar methodology (but blinded) of $1200 \mathrm{MICU}$ patients, IIT to keep glucose levels between $80-110 \mathrm{mg} / \mathrm{dl}$ was compared to conventional therapy aiming at levels below $180 \mathrm{mg} / \mathrm{dl} .{ }^{14}$ In this study, IIT had no impact upon mortality, yet reduced duration of ventilatory support, acute renal failure, and ICU stay. ${ }^{14}$ Interestingly, among patients treated with IIT, those who stayed in the ICU for 3 or more days had less in-hospital mortality whereas those staying for less time had increased in-hospital mortality, and those staying for 7 or more days had lower rates of neurological complications. ${ }^{14}$ IIT patients also experienced more episodes of hypoglycemia, which may have been in part due to the greater frequency of patients with renal and hepatic failure in the MICU. ${ }^{14}$

In a randomized unblinded single-center study of $504 \mathrm{MICU}$ and SICU patients, treatment strategies comparing goal glucose levels between $80-110 \mathrm{mg} / \mathrm{dl}$ and $180-200 \mathrm{mg} / \mathrm{dl}$ were compared. ${ }^{15}$ Mortality rates were similar between the two (36.6\% vs. $32.4 \%)$, but hypoglycemic episodes were greater in the IIT group ( $8.5 \%$ vs. $1.7 \%){ }^{15}$ In the VISEP ${ }^{*}$ study of over 600 septic patients, which was terminated prematurely for safety reasons, IIT [glucose $80-110 \mathrm{mg}$ / dl] was associated with a greater rate of severe hypoglycemia ( $17 \%$ vs. $4.1 \%$ ) and more frequent serious adverse events ( $10.9 \%$ vs. $5.2 \%)$, red-cell transfusions, and duration of ICU stay, than conventional therapy $[180-200 \mathrm{mg} / \mathrm{dl}]{ }^{16}$

The GLUCONTROL study of 1078 medical and surgical ICU patients was also terminated prematurely due to safety reasons and excessive protocol violations, but demonstrated that IIT [glucose $80-110 \mathrm{mg} / \mathrm{dl}$ ] versus intermediate glucose control [140-180mg/dl] resulted in similar mortality rates $(15.3 \%$ vs. $17.2 \%) .{ }^{17}$ Hypoglycemic events were also increased by IIT $(8.7 \%$ vs. $2.7 \%)$, and a greater mortality was observed in these patients. ${ }^{17}$ The NICESUGAR $^{\dagger}$ study of 6104 general ICU patients

* Volume Substitution and Insulin Therapy in Severe Sepsis

${ }^{\dagger}$ Normoglycemia in Intensive Care Evaluation-Survival Using 
revealed an increased mortality rate among IIT patients [glucose $80-110 \mathrm{mg} / \mathrm{dl}, 27.5 \%$ mortality] compared to conventional therapy [140-180mg/dl, 24.9\% mortality] and greater rates of hypoglycemia (6.8\% vs. $0.5 \%) .{ }^{18}$

\section{Neurological Patients}

In a subgroup analysis of patients with cerebral injury from the original SICU study, most of whom experienced a cerebrovascular event or had neurosurgery for various reasons, IIT resulted in a reduction in intracranial pressures, epileptic episodes, critical illness polyneuropathy, need for vasopressors, and diabetes insipidus. ${ }^{9}$ In a small study of head trauma patients, IIT resulted in more hypoglycemic events, but no improvement in mortality, neurological outcome, or infections. ${ }^{19}$ One retrospective study of patients with subarachnoid hemorrhage showed no benefit to aggressive hyperglycemic management in terms of neurological outcome, vasospasm and delayed cerebral ischemia. ${ }^{20}$

A prospective observational microdialysis study of SAH patients found elevated glucose levels to be associated with increased lactate/pyruvate ratios and increased mortality. ${ }^{21}$ Conversely, a more recent study of head trauma patients showed that IIT resulted in lower cerebral glucose concentrations (without a change in cerebral glucose metabolic rate), with increases in global oxygen extraction fraction. ${ }^{22}$ This study also showed elevated lactate/pyruvate ratios, and increased glutamate concentrations in patients treated with IIT, particularly with serum glucose levels below $80 \mathrm{mg} / \mathrm{dl} .{ }^{22}$ Mortality did not differ between the intensive and regular insulin therapy groups. ${ }^{22}$

\section{Review Articles and Meta-Analyses}

A review article focusing on the VISEP, GLUCONTROL, and NICE-SUGAR studies concluded that the available evidence supports treatment of glucose levels $>180 \mathrm{mg} / \mathrm{dl}$, thus effectively discouraging aggressive glycemic control as defined by most clinical trials, and notes the potential for maximum benefit at levels $<140 \mathrm{mg} / \mathrm{dl} .^{3}$ In assessing the available data cumulatively, a 2008 meta-analysis of over 8000 patients concluded that IIT reduces risk for septicemia, but at the expense of more hypoglycemic episodes $(<40 \mathrm{mg} / \mathrm{dl})$ and without any impact on in-hospital mortality. ${ }^{6}$ Current guidelines for critically ill patients presented by the American Diabetes Association recommend starting treatment at glucose levels $>180 \mathrm{mg} / \mathrm{dl}$,

Glucose Algorithm Regulation with a goal of maintaining levels $<140 \mathrm{mg} / \mathrm{dl}$, and discourage aggressive treatment to reach levels $<110 \mathrm{mg} / \mathrm{dl}^{23}$

\section{Conclusions}

Despite the clear association between hyperglycemia and adverse outcomes, clinical studies have failed to definitively provide evidence for a benefit to antihyperglycemic therapy, and certainly have not identified a precise target range for glucose levels. This leads one to wonder whether hyperglycemia may represent a physiological protective response, and therefore a natural evolutionarily derived reaction to illness that does not mandate treatment. As recently stated by one author, "the ultimate proof that hyperglycemia is an independent risk factor for ICU mortality in critically ill patients is lacking". ${ }^{3}$

As is the case with many situations in medicine, there is an innate belief that "abnormal" laboratory values warrant correction. Until the completion of trials demonstrating the absence of benefit (and in fact a detriment) from transfusions for anemia in ICU patients, the belief was to normalize hemoglobin counts so as to maintain levels of 10 or greater. Now, with the completion of adequate trials, the standard of care has become to allow hemoglobin levels as low as $7 .{ }^{24}$ Thus, this tendency to treat "abnormal" glucose values may actually counteract a natural reactive (and possibly protective) process, which may simply represent the natural inclination by physicians to assume a need for treatment of aberrant values.

1. Vanhorebeek I, Lagouche L, Van den Berghe G: Tight Blood Glucose Control - What is the Evidence? Crit Care Med 35:496-502, 2007.

2. Van den Berghe G, Wouters P, Bouillon R: Outcome Benefit of Intensive Insulin Therapy in the Critically Ill - Insulin Dose Versus Glycemic Control. Crit Care Med 31:359-366, 2003.

3. Preiser J, Devos P: Clinical Experience with Tight Glucose Control By Intensive Insulin Therapy. Crit Care Med 35:503 507, 2007.

4. Egi M, Bellomo R, Stachowski E, French C, Hart G: Variability of Blood Glucose Concentration and Short Term Mortality in Critically Ill Patients. Anesthesiology 105:244252, 2006.

5. Finney S, Zekveld C, Elia A, Evans T: Glucose Control and Mortality in Critically Ill Patients. JAMA 290:2041-2047, 2003.

6. Wiener R, Wiener D, Larson R: Benefits and Risks of Tight Glucose Control in Critically Ill Adults. JAMA 300:933944, 2008.

7. Van den Berghe G, Wouters P, Weekers F, Verwaest C, Bruyninckx F, Schetz M, Vlasselaers D, Ferdinande P, Lauwers P, Bouillon R: Intensive Insulin Therapy in Critically Ill Patients. NEJM 345:1359-1367, 2001.

8. Frontera J, Fernandez A, Claassen J, Schmidt M, Schumacher $\mathrm{H}$, Wartenberg K, Temes R, Parra A, Ostapkovich N, Mayer S: Hyperglycemia After SAH - Predictors, Associated Compications, and Impact on Outcome. Stroke 37:199-203, 2006.
9. Van den Berghe G, Schoonheydt K, Becx P, Bruyninckx F, Wouters P: Insulin Therapy Protects the Central and Peripheral Nervous System of Intensive Care Patients. Neurology 64:1348-1353, 2005.

10. Bochicchio G, Sung J, Joshi M, Bochicchio K, Tracy K, Scalea T: Persistant Hyperglycemia is Predictive of Outcome in Critically Ill Trauma Patients. J Trauma 58:921-924, 2005.

11. Capes S, Hunt D, Malmberg K: Stress Hyperglycaemia and Increased Risk of Death After Myocardial Infarction in Patients with and without Diabetes - A systematic review. Lancet 355:773-778, 2000 .

12. Capes S, Hunt D, Malmberg K: Stress Hyperglycemia and Prognosis of Stroke in Nondiabetic and Diabetic Patients - A systematic review. Stroke 32:2426-2432, 2001.

13. Krinsley J: Effect of an Intensive Glucose Management Protocol on the Mortality of Critically Ill Adult Patients. Mayo Clin Proc 79:992-1000, 2004.

14. Van den Berghe G, Wilmer A, Hermans G, Meersseman W, Wouters P, Milants I, Wijngaerden E, Bobbaers H, Bouillon $R$ : Intensive Insulin Therapy in the Medical ICU. NEJM 354:449-461, 2006

15. De la Rosa G, Donado J, Restrepo A, Quintero A, Gonzalez L, Saldarriaga N, Bedoya M, Toro J, Velasquez J, Valencia J, Arango C, Aleman P, Vasquez E, Chavarriaga J, Yepes A, Pulido W, Cadavid C: Strict Glycaemic Control in Pateints Hospitalized in a Mixed Medical and Surgical Intenssive Care Unit. Crit Care 12:1-9, 2008.

16. Brunkhorst F, Engel C, Bloos F, Hellmann A, Ragaller M, Weiler N, Moerer O, Gruendling M, Oppert M, Grond S, Olthoff D, Jaschinski U, Stefan J, Rossaint R, Welte T, Schaefer M, Kern P, Kuhnt E, Kiehntopf M, Hartog C, Natanson C, Loeffler M, Reinhart K: Intensive Insulin Therapy and Pentastarch Resuscitation in Severe Sepsis. NEJM 358:125-139, 2008.

17. Preiser J, Devos P, Ruiz-Santana S, Melot C, Annane D, Groeneveld J, Iapichino G, Leverve X, Nitenberg G, Singer P, Wernerman J, Joannidis M, Stecher A, Chiolero R: A Prospective Randomized Multicenter Controlled Trial on Tight Glucose Control by Intensive Insulin Therapy in Adult Intensive Care Units. Int Care Med 35:1738-1748, 2009.

18. NICE-SUGAR Study Investigators: Intensive Versus Conventional Glucose Control in Critically Ill Patients. NEJM 360:1283-1297, 2009

19. Bilotta F, Caramia R, Cernak I, Paoloni P, Doronzio A, Cuzzone V, Santoro A, Rosa G: Intensive Insulin Therapy After Severe Traumatic Brain Injury. Neurocritical Care 9:159-166, 2008

20. Latorre J, Chou S, Nogueira R, Singhal A, Carter B, Ogilvy C, Rordorf G: Effective Glycemic Control with Aggresive Hyperglycemia Management is Associated with Improved Outcome in Aneurysmal Subarachnoid Hemorrhage. Stroke 40:1644-1652, 2009.

21. Schlenk F, Vajkoczy P, Sarrafzadeh A: Inpatient Hyperglycemia Following Aneurysmal Subarachnoid Hemorrhage - Relation to Cerebral Metabolism and Outcome. Neurocritical Care 11:56-63, 2009.

22. Vespa P, Boonyaputthikul R, McArthur D, Miller C, Etchepare M, Bergsneider M, Glenn T, Martin N, Hovda D: Intensive Insulin Therapy Reduces Microdialysis Glucose Values without Altering Glucose Utilization or Improving the Lactate/Pyruvate Ratio After Traumatic Brain Injury. Crit Care Med 34:850-856, 2006.

23. Moghissi E, Korytkowski M, Dinardo M, Einhorn D, Hellman R, Hirsch I, Inzucchi S, Ismail F, Kirkman S, Umpierrez G: American Association of Clinical Endocrinologists and American Diabetes Association Consensus Statement on Inpatient Glycemic Control. Diabetes Care 6:1119-1131, 2009.

24. Hebert P, Wells G, Blajchman M, Marshall J, Martin C, Pagliarello G, Tweeddale M, Schweitzer I, Yetisir E: A Multicenter Randomized Controlled Clinical Trial of Transfusion Requirements in Critical Care. NEJM 340:409417, 1999. 